\title{
Genotype $\times$ environment interactions with lettuce (Lactuca L.) in relation to the development of genotypes for growing under pcor energy conditions
}

\author{
A. H. Eenink and L. Smeets \\ Institute for Horticultural Plant Breeding (IVT), Wageningen, the Netherlands
}

Key words: lettuce, Lactuca, temperature, light, genotype $\times$ environment interactions

\section{Summary}

Experiments were done in 1975 with 20 genotypes (G) and in 1976 with 10 genotypes from the IVT Lactuca gene bank. These genotypes grew rather well under poor energy conditions. Plants were grown in glasshouses at constant temperatures (T) of $10,14,17$ and $20^{\circ} \mathrm{C}$ and two light intensities (L). In 1976, they were also grown in a normal glasshouse at minimum day and night temperatures of 9 and $5^{\circ} \mathrm{C}$, respectively. The glasshouse was ventilated when the temperature exceeded $20{ }^{\circ} \mathrm{C}$.

$\mathrm{G} \times \mathrm{T}, \mathrm{G} \times \mathrm{L}, \mathrm{L} \times \mathrm{T}$ and $\mathrm{G} \times \mathrm{T} \times \mathrm{L}$ interactions were found for plant weight and leaf number and to a certain extent they depended on the developmental phase. Mostly the main effects ( $T, L$ and $G$ ) were more important than the interactions.

Genotype $\times$ environment interactions were also found by Eberhart-Russell analysis.

The occurrence of interactions has certain implications for plant breeding. Genotypes should be developed that can grow well under poor energy conditions and can react very positively to incidental better energy conditions. Possible selection environments have been discussed.

\section{Introduction}

In 1973 a breeding programme was started to develop lettuce that can grow rapidly under poor energy conditions in winter. To this end about 1000 genotypes from the IVT Lactuca gene bank were screened (Eenink, 1977). Several genotypes were found which grew more rapidly than normal winter varieties.

During screening in the glasshouse in winter both temperature and light intensity varied. It was therefore important to analyse the response of the selected genotypes to these climatic factors under controlled conditions to obtain a better understanding of their growth patterns. Research on genotype $\times$ environment interactions was carried out and consequences for breeding were envisaged. The importance of such 
interactions may have implications for the type of selections to be developed and also for the selection environments which will have to be used. The results are given in this paper.

\section{Materials and methods}

Table 1 shows the genotypes (PIVT numbers) which were used in experiments in 1975 and 1976. Four of these genotypes were included in both experiments. Wild species and cultivated types were involved.

The plants were grown in glasshouses of the IVT phytotron at constant temperatures of $10,14,17$ and $20^{\circ} \mathrm{C}$ at two light intensities in two randomized blocks per environment. The two light intensities were chosen to simulate an autumn/winter with rather good and rather poor light conditions, respectively. The two light conditions were (1) day light intensified from $08 \mathrm{~h} 00-16 \mathrm{~h} 00$ with mercury light from

Table 1. Genotypes (PIVT numbers) of the IVT Lactuca gene bank investigated in 1975 and/or 1976 for interaction with environment.

\begin{tabular}{|c|c|c|c|c|}
\hline $\begin{array}{l}\text { PIVT } \\
\text { No }\end{array}$ & Species or cultivar & Type & $\begin{array}{l}\text { Origin (gene } \\
\text { bank, bot. } \\
\text { garden, } \\
\text { seed firm) }\end{array}$ & $\begin{array}{l}\text { Year(s) of } \\
\text { investigation }\end{array}$ \\
\hline 9 & Amanda Plus & Cultivated, heading & Neth. & 1975 \\
\hline 85 & Celtuce & Cultivated, non-heading & USA & 1975 \\
\hline 91 & Kakichisago red & Cultivated, non-heading & Japan & 1975,1976 \\
\hline 105 & Deci Minor & Cultivated, heading & Neth. & 1975 \\
\hline 197 & Kakichisago white & Cultivated, non-heading & Jepan & 1975 \\
\hline 246 & L. scariola & Wild, non-heading & France & 1975,1976 \\
\hline 392 & L. sativa PI 220665 & Cultivated, non-heading & Afghan. & 1975 \\
\hline 417 & L. serriola PI 251246 & Wild, non-heading & Egypt & 1975,1976 \\
\hline 440 & L. sativa PI 274359 & Cultivated, non-heading & Poland & $1975^{\circ}$ \\
\hline 444 & L. serriola PI 274457 & Wild, non-heading & Germany & 1975 \\
\hline 632 & Irish Vin & Cultivated, non-heading & Germany & 1976 \\
\hline 634 & Irish & Cultivated, non-heading & China & 1976 \\
\hline \multirow[t]{2}{*}{715} & L. sativa $\mathrm{ssp}$. & & & \\
\hline & augustana & Cultivated, non-heading & Chechosl. & 1976 \\
\hline 765 & Kaliber & Cultivated, heading & Neth. & 1976 \\
\hline 787 & Troppo & Cultivated, heading & Neth. & 1976 \\
\hline 818 & L. scariola & Wild, non-heading & Hung. & 1976 \\
\hline 963 & Ravel & Cultivated, heading & Neth. & 1975 \\
\hline 964 & Rossini & Cultivated, heading & Neth. & 1975 \\
\hline 965 & Feodora & Cultivated, heading & Neth. & 1975 \\
\hline 967 & Mandela & Cultivated, heading & Neth. & 1975 \\
\hline 968 & Type 451 LM & Cultivated, heading & Neth. & 1975 \\
\hline 969 & Orba & Cultivated, heading & Neth. & 1975 \\
\hline 971 & Cynthia & Cultivated, heading & Neth. & 1975 \\
\hline 972 & Alicia & Cultivated, heading & Neth. & 1975 \\
\hline 973 & Renate & Cultivated, heading & Neth. & 1975,1976 \\
\hline 974 & Helia & Cultivated, heading & Neth. & 1975 \\
\hline
\end{tabular}




\section{GENOTYPE $\times$ ENVIRONMENT INTERACTIONS WITH LETTUCE}

HPL/N $400 \mathrm{~W}$ lamps, light intensity $6 \mathrm{~W} / \mathrm{m}^{2}$ (highest intensity, HI), and (2) natural light reduced to about $75 \%$ by shading the plants with netting for the same period as above (lowest intensity, LI). Total outside radiation during the experimental period (October, November and December) of 1975 and 1976 was about the same, namely 336 and $328 \mathrm{MJ} / \mathrm{m}^{2}$, respectively.

At 36, 62 and 81 days from sowing ( 2 October) in the 1975 experiment and 34, 60 and 83 days from sowing ( 7 October) in the 1976 experiment, from each environment 5,2 and 3 plants, respectively, per genotype per block were harvested. Harvest was determined by the time when plants had become so large as to cause mutual shading in an environment. Fresh weight of the tops and the number of expending leaves were determined. Leaves were counted to investigate whether the relationship between plant weight and leaf number (Eenink, 1977) depends on temperature and light intensity.

To compare the behaviour of the genotypes in the phytotron environments with their behaviour in the environment used for screening of the gene bank, in 1976 these genotypes were also grown in a glasshouse under minimum day and night temperatures of 9 and $5{ }^{\circ} \mathrm{C}$, respectively, and natural light conditions. The glasshouse was ventilated when temperature exceeded $20^{\circ} \mathrm{C}$.

These plants, grown in four randomized blocks each of five plants per genotype, were harvested once ( 83 days from sowing).

Analyses of variance were carried out per environment and over all environments for plant weight and leaf number.

\section{Results}

\section{Analyses of variance per environment}

In Fig. 1-4 the means for plant weight and leaf number per environment of the 1975 and 1976 experiment are given. It appears that in early developmental phases (harvest 1) both for plant weight and leaf number lowest means were obtained at $10{ }^{\circ} \mathrm{C}$ $\mathrm{LI}$ and highest means at $20^{\circ} \mathrm{C} \mathrm{HI}$. When plants grew older, lowest means still occurred at $10^{\circ} \mathrm{C} \mathrm{LI}$ but highest means for plant weight were obtained at $17^{\circ} \mathrm{C} \mathrm{HI}$ and for leaf number at $17{ }^{\circ} \mathrm{C}$ or $20^{\circ} \mathrm{C} \mathrm{HI}$.

Analysis of variance per environment showed that in each environment significant differences occurred between genotypes for plant weight and leaf number. No systematic differences of $F$ genotypes between harvest times were observed for these characters. However, with all harvests certain environments with large $F$ genotypes occurred.

In Fig. 1-4 the relatively largest $F$ values for plant weight or leaf number are indicated next to the corresponding environments. These environments are more discriminating than others and thus most favourable for selecting for such characters provided no important genotype $\times$ environment interactions occur.

Comparison of harvest 3 of the phytotron trials in 1976 with the corresponding harvest of the glasshouse trial shows that both for plant weight and leaf number, means and $\mathrm{F}$ genotypes at $14^{\circ} \mathrm{C} \mathrm{LI}$ in the phytotron agreed fairly well with those 

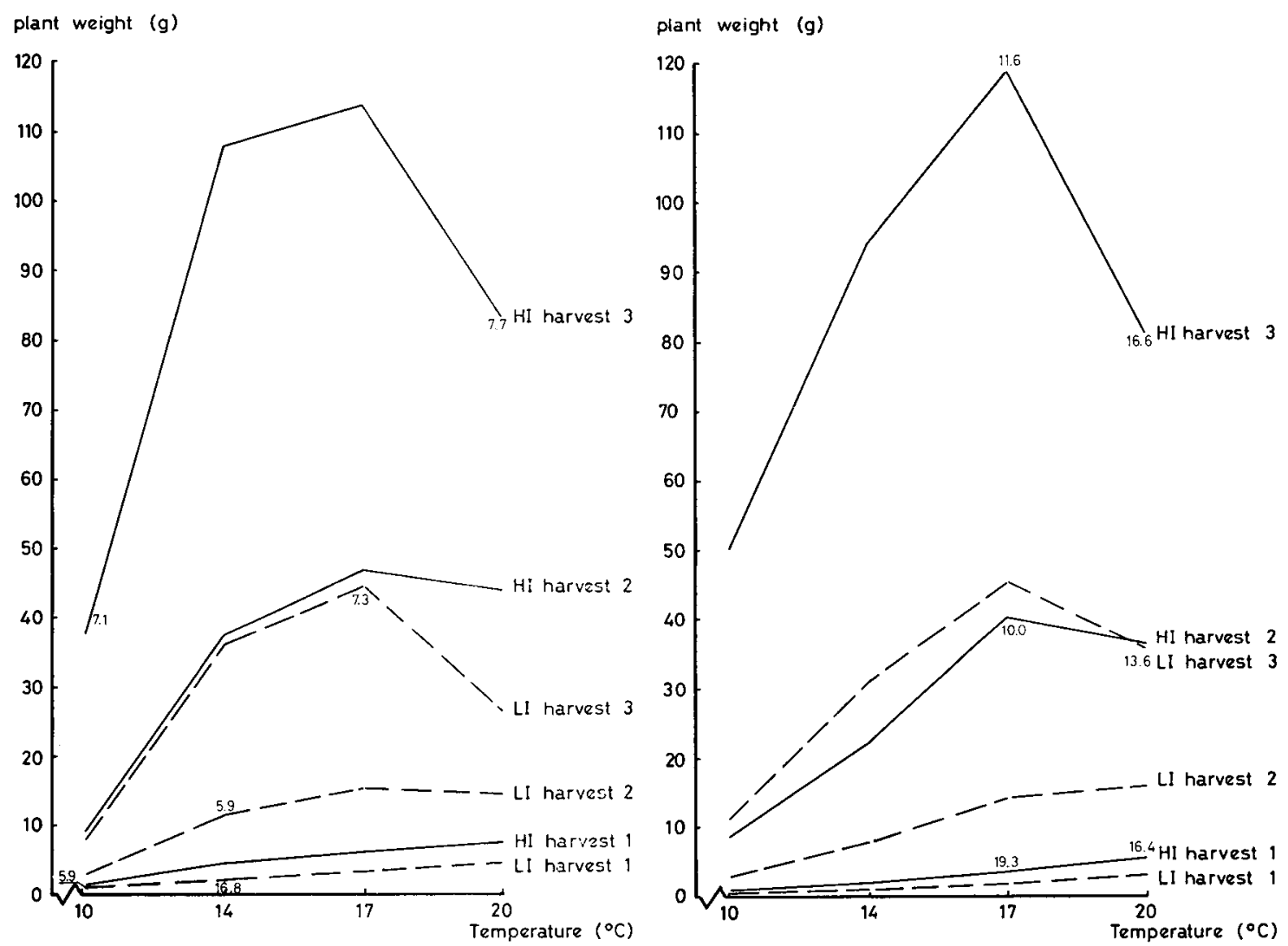

Fig. 1 (left). Overall means per environment for plant weight in 1975. HI $=$ highest intensity; $\mathbf{L I}=$ lowest intensity. Figures indicate $\mathrm{F}$ genotypes.

Fig. 2 (right). Overall means per environment for plant weight in 1976. HI = highest intensity; $\mathbf{L I}=$ lowest intensity. Figures indicate $\mathbf{F}$ genotypes.

from the glasshouse. The only exception was the $F$ value for leaf number in the glasshouse trial which was extremely large.

\section{Analyses of variance for plant weight over all environments}

To investigate genotype $\times$ environment interactions, analyses of variance over all environments were carried out per harvest time. As the analyses of variance per environment mentioned before revealed no systematic differences between environments for coefficients of variation, In transformation was carried out which stabilized the variance. Table 2 gives the results for $\ln$ plant weight at three harvest times in 1975 and 1976. 

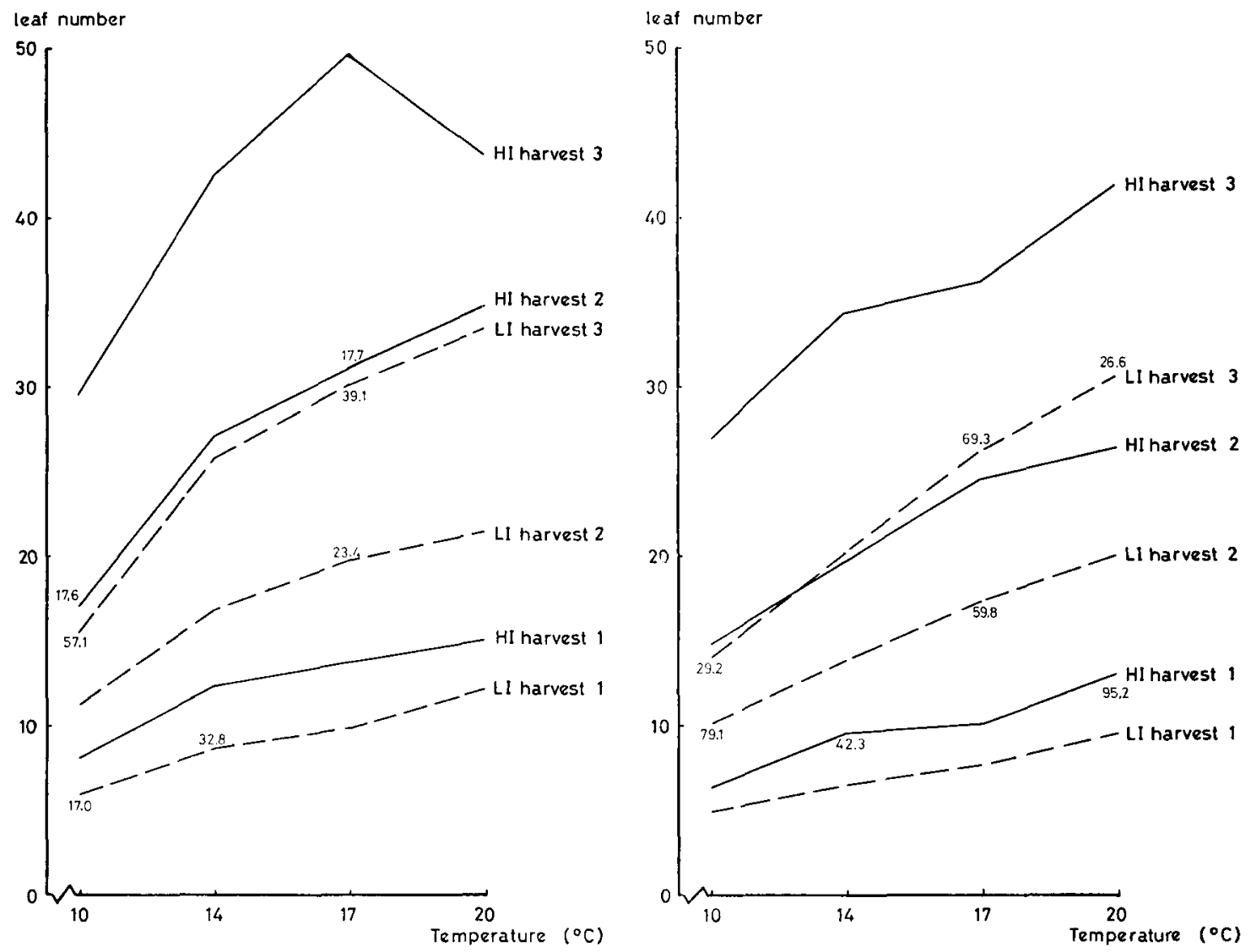

Fig. 3 (left). Overall means per environment for leaf number in 1975 . HI $=$ highest intensity; $\mathrm{LI}=$ lowest intensity. Figures indicate $\mathrm{F}$ genotypes.

Fig. 4 (right). Overall means per environment for leaf number in $1976 . \mathrm{HI}=$ highest intensity; $\mathrm{LI}=$ lowest intensity. Figures indicate $\mathrm{F}$ genotypes.

\section{Main effects}

In both experiments with almost all harvests significant differences occurred between temperatures $(T)$, between light intensities (L) and between genotypes (G).

\section{Interactions}

Compared with the main effects the interactions mostly were rather small. At later developmental phases (harvest 3) more significant interactions were found than when plants were rather young (harvest 1 and 2).

$-G \times T$. Table 2 shows that in both experiments $G \times T$ interaction was significant with harvest 2 and 3 . Table 3 gives mean plant weights with harvest 3 per genotype per environment in 1975 and 1976. In this table a discrimination is made for cultivated types and wild species and for heading versus non-heading types. At both 
Table 2. Analyses of variance for In plant weight at three harvest times in 1975 and 1976.

\begin{tabular}{|c|c|c|c|c|c|c|c|}
\hline \multirow[t]{2}{*}{ Source } & \multirow[t]{2}{*}{ d.f. } & \multicolumn{2}{|l|}{ Harvest 1} & \multicolumn{2}{|l|}{ Harvest 2} & \multicolumn{2}{|l|}{ Harvest 3} \\
\hline & & $\mathrm{MS} \cdot 10^{-3}$ & $\mathrm{~F}$ & $\mathrm{MS} \cdot 10^{-3}$ & $\mathbf{F}$ & $\mathrm{MS} \cdot 10^{-3}$ & $\mathbf{F}$ \\
\hline \multicolumn{8}{|l|}{1975 experiment } \\
\hline Temperature (T) & 3 & 526.7 & $159.6^{* *}$ & 507.1 & $3339.7 * *$ & 313.1 & $26.9^{* *}$ \\
\hline Light intensity (L) & 1 & 460.2 & $139.4 * *$ & 1066.5 & $7023.8^{* *}$ & 1051.1 & $90.3 * *$ \\
\hline $\mathrm{T} \times \mathrm{L}$ & 3 & 3.3 & 1.4 & 0.15 & 0.02 & 11.6 & 1.2 \\
\hline Replicates $\times \mathbf{T} \times \mathbf{L}$ & 8 & 2.4 & & 6.4 & & 9.7 & \\
\hline Genotypes (G) & 19 & 32.9 & $131.6^{* *}$ & 36.5 & $48.6^{* *}$ & 23.8 & $25.8 * *$ \\
\hline$G \times T$ & 57 & 0.4 & 1.5 & 1.9 & $2.5 * *$ & 2.4 & $2.7 * *$ \\
\hline $\mathrm{G} \times \mathrm{L}$ & 19 & 0.3 & 1.3 & 0.2 & 0.3 & 1.3 & 1.5 \\
\hline $\mathbf{G} \times \mathbf{T} \times \mathbf{L}$ & 57 & 0.3 & $1.6^{*}$ & 0.8 & $4.9^{*}$ & 0.9 & $6.8^{* *}$ \\
\hline Rest & 152 & 0.2 & & 0.2 & & 0.1 & \\
\hline \multicolumn{8}{|l|}{1976 experiment } \\
\hline Temperature $(\mathrm{T})$ & 3 & 257.6 & $420.4 * *$ & 215.8 & $173.6^{* *}$ & 85.7 & 6.5 \\
\hline Light intensity (L) & 1 & 198.9 & $324.7 * *$ & 403.1 & $324.4 * *$ & 422.6 & $32.1^{*}$ \\
\hline $\mathrm{T} \times \mathrm{L}$ & 3 & 0.6 & 0.9 & 1.2 & 2.5 & 13.2 & $137.9 * *$ \\
\hline Replicates $\times \mathbf{T} \times \mathbf{L}$ & 8 & 0.7 & & 0.5 & & 0.1 & \\
\hline Genotypes (G) & 9 & 7.0 & $39.4 * *$ & 9.2 & $29.0 * *$ & 14.2 & $21.5^{* *}$ \\
\hline$G \times T$ & 27 & 0.3 & 1.6 & 1.0 & $3.2^{* *}$ & 3.1 & $4.6^{* *}$ \\
\hline$G \times L$ & 9 & 0.3 & 1.6 & 0.3 & 1.0 & 2.2 & $3.3 * *$ \\
\hline $\mathrm{G} \times \mathrm{T} \times \mathrm{L}$ & 27 & 0.2 & 1.5 & 0.3 & 0.9 & 0.7 & $1.9^{*}$ \\
\hline Rest & 72 & 0.1 & & 0.4 & & 0.4 & \\
\hline
\end{tabular}

$* \mathrm{P}<0.05 ; \quad * * \mathrm{P}<0.01$.

light intensities the majority of the PIVT numbers reached their maximum plant weight at $17{ }^{\circ} \mathrm{C}$. A few genotypes did so at 14 or $20^{\circ} \mathrm{C}$. This difference in reaction to temperature implies $\mathrm{G} \times \mathrm{T}$ interaction. The results in this table do not show any difference between cultivated versus wild type or heading versus non-heading type regarding reaction to temperature.

$-G \times L$. Only with harvest 3 in 1976 did a significant $\mathrm{G} \times \mathrm{L}$ interaction occur as demonstrated in Fig. 5-8. It can be seen that PIVT Nos 91, 632 and 715 showed at all temperatures larger differences between plant weight at $\mathrm{HI}$ and LI than other genotypes. Similar tendencies were found with harvests 1 and 2 of this year. These genotypes, which reacted particularly strongly to $\mathrm{HI}$, were non-heading while the genotypes which did not were heading or non-heading.

$-T \times L$. Differences between temperatures for the effect of light intensity imply a $\mathrm{T} \times \mathrm{L}$ interaction which was only significant with harvest 3 in 1976. In Table 4 both the absolute effect of light intensity (HI-LI) and the relative effect (HI/LI) per temperature with harvest 3 in 1976 are shown.

The absolute effect was smallest at $10^{\circ} \mathrm{C}$, increased when temperature increased and was again smaller at $20^{\circ} \mathrm{C}$. So the greatest mean effect of light intensity was obtained with 14 and $17{ }^{\circ} \mathrm{C}$ which were also temperatures where, averaged over all genotypes, growth was strong.

The relative effect of light intensity (HI/LI) was greatest at $10^{\circ} \mathrm{C}$ and decreased 


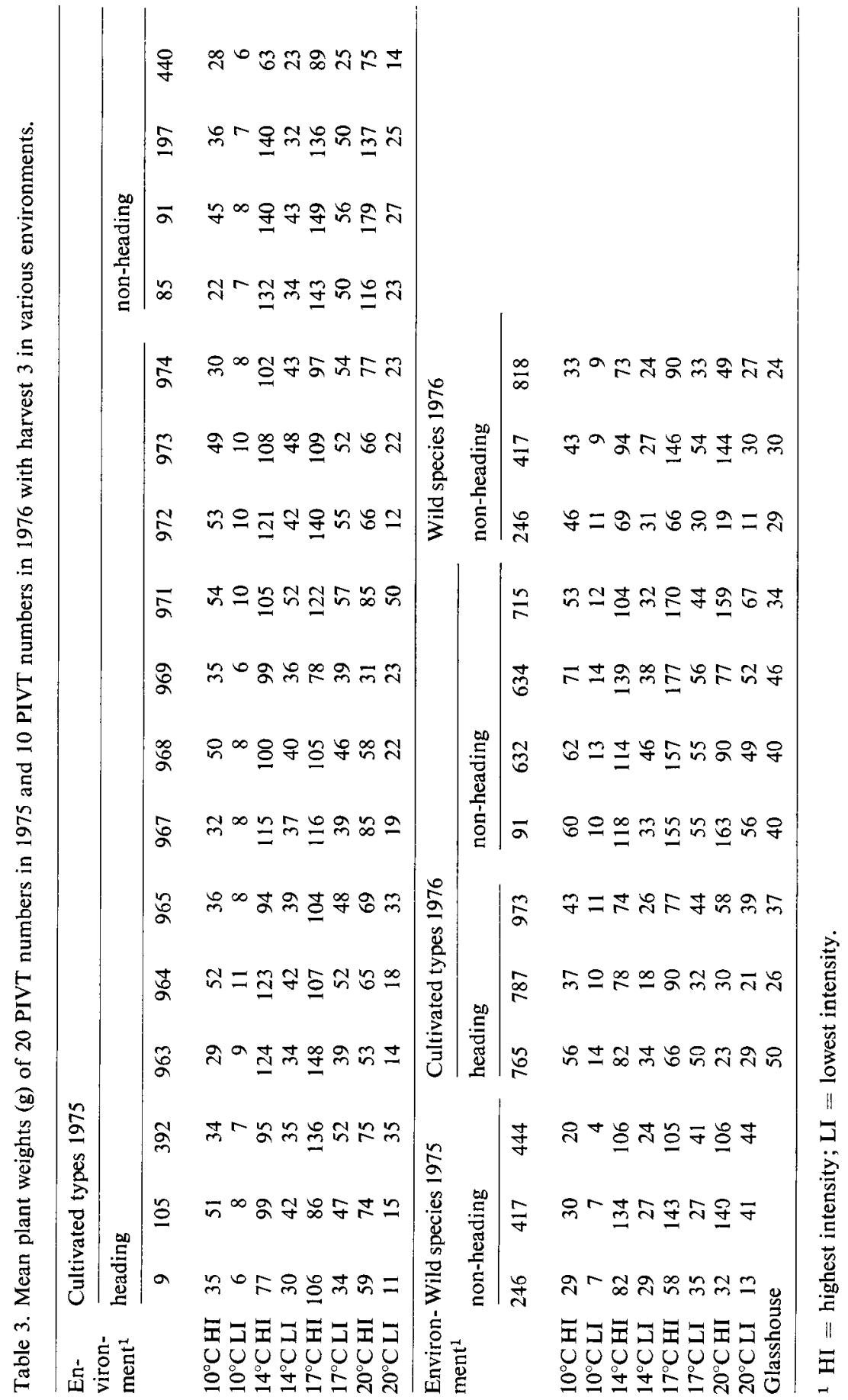



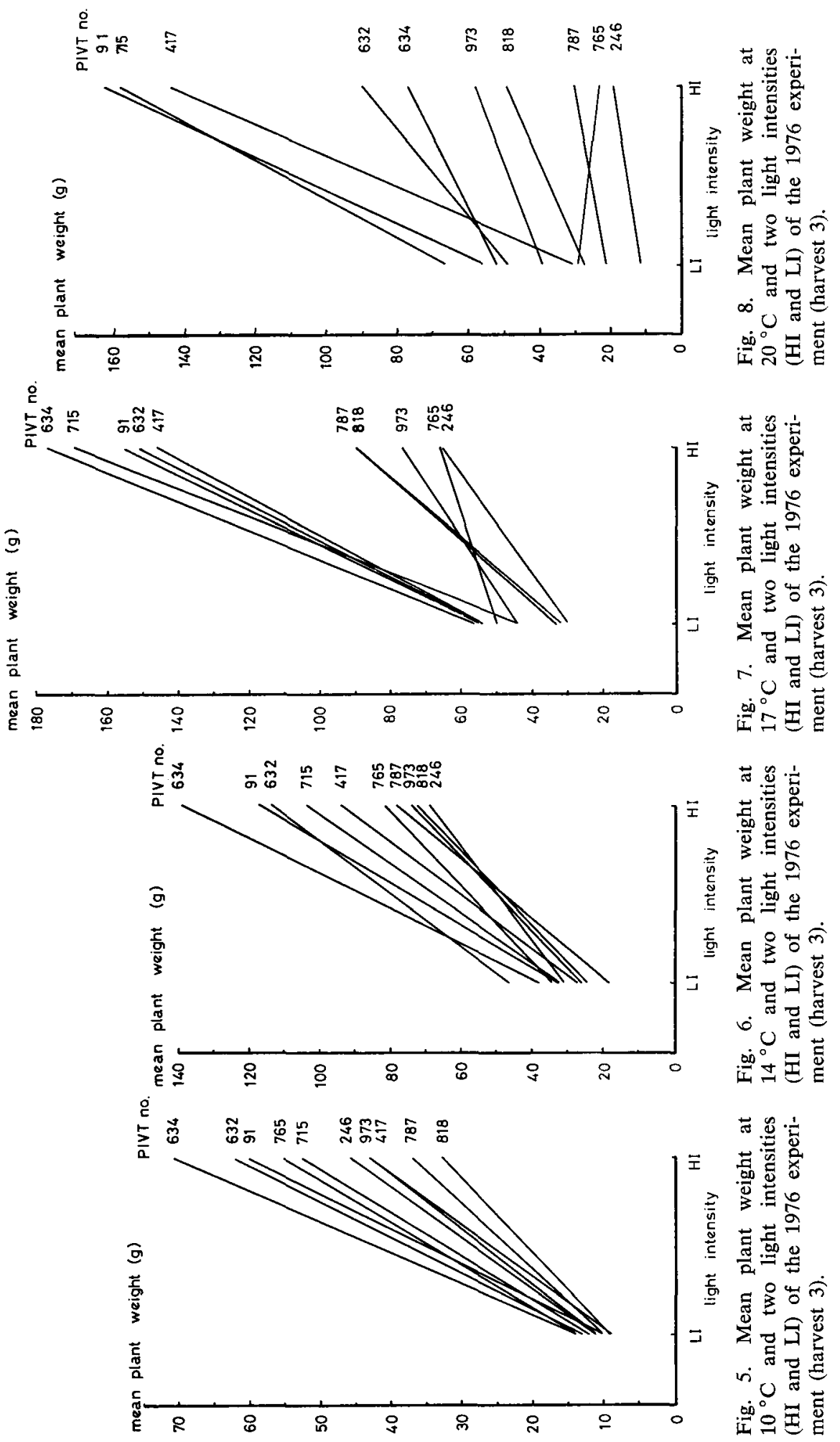
GENOTYPE $\times$ ENVIRONMENT INTERACTIONS WITH LETTUCE

Table 4. Effect of light intensity on plant weight (g) at four temperatures with harvest 3 in 1976.

Light intensity

Highest intensity (HI)

Lowest intensity (LI)

Absolute effect (HI-LI)

Relative effect $(\mathrm{HI} / \mathrm{LI})$

\section{Mean plant weight (g)}

$10^{\circ} \mathrm{C} \quad 14^{\circ} \mathrm{C} \quad 17^{\circ} \mathrm{C} \quad 20^{\circ} \mathrm{C}$

$\begin{array}{llll}50 & 94 & 119 & 81\end{array}$

$\begin{array}{llll}11 & 31 & 45 & 38\end{array}$

$\begin{array}{llll}39 & 63 & 74 & 43\end{array}$

$\begin{array}{llll}4.6 & 3.0 & 2.6 & 2.1\end{array}$

as temperature increased. An explanation for the differences in $\mathrm{HI} / \mathrm{LI}$ effect might be the mutual shading of leaves within plants. This shading will occur earlier at $\mathrm{HI}$ than at LI if temperature increases.

- $G \times T \times L$. With all harvests of Experiment 1 and harvest 3 of Experiment 2 significant $\mathrm{G} \times \mathrm{T} \times \mathrm{L}$ interactions occurred. With about $30 \%$ of the genotypes investigated in 1975 and 1976, representing all groups distinguished in Table 3, maximum plant weight at $\mathrm{HI}$ was obtained at a lower temperature than maximum plant weight at LI. It should be noticed, however, that in all these cases no clear optimum temperature at $\mathrm{LI}$ or $\mathrm{HI}$ occurred. $\mathrm{G} \times \mathrm{T} \times \mathrm{L}$ interaction can also be seen from Fig. 5-8. These figures show that the reaction to light intensity of certain genotypes depended on temperature. For instance, with a genotype such as PIVT 765 the positive effect of additional illumination was great at $10^{\circ} \mathrm{C}$ but small or even absent at higher temperatures such as 17 or $20^{\circ} \mathrm{C}$. This contrasts with PIVT 417 in which the effect of $\mathrm{HI}$ was small at $10^{\circ} \mathrm{C}$ but strong at high(er) temperatures, for example $17{ }^{\circ} \mathrm{C}$. Since PIVT 765 had a rather low optimum temperature and PIVT 417 a rather high optimum temperature, the effect of light intensity for these genotypes seems to be strongest around the optimum temperature for growth. Such a relationship did not occur with the majority of the other genotypes.

- $G \times$ harvest. A comparison of sequence numbers for genotypes per harvest for the three harvests per year involved, did not show clear genotype $\times$ harvest interactions.

- $G \times$ year. The possible existence of a genotype $\times$ year interaction was investigated by using the four PIVT numbers which were tested both in 1975 and 1976 (see Table 1). From a comparison of the sequences for overall mean plant weight per genotype with harvest 3 in both years, it appeared that no such interactions clearly occurred for this character. Nevertheless certain genotypes behaved differently in 1975 and 1976 in some environments.

Comparison of plant weight in phytotron environments with that in the glasshouse environment

The sequence numbers of the genotypes for plant weight in the eight phytotron environments were compared with the sequence in the environment used for screening in the glasshouse. They did not agree, though there was a certain similarity 
Table 5. Analyses of variance for In leaf number at three harvest times in 1975 and 1976.

\begin{tabular}{|c|c|c|c|c|c|c|c|}
\hline \multirow[t]{2}{*}{ Source } & \multirow[t]{2}{*}{ d.f. } & \multicolumn{2}{|l|}{ Harvest 1} & \multicolumn{2}{|c|}{ Harvest 2} & \multicolumn{2}{|l|}{ Harvest 3} \\
\hline & & $\mathrm{MS} \cdot 10^{-3}$ & $\mathbf{F}$ & $\mathrm{MS} \cdot 10^{-3}$ & $F$ & $\mathrm{MS} \cdot 10^{-3}$ & F \\
\hline \multicolumn{8}{|l|}{1975 experiment } \\
\hline Temperature $(\mathrm{T})$ & 3 & 66.7 & $78.2^{* *}$ & 68.8 & $343.6 * *$ & $51.9 * *$ & $14.3^{* *}$ \\
\hline Light intensity (L) & 1 & 73.1 & $85.7^{* *}$ & 158.9 & $793.8 * *$ & 165.8 & $45.5 * *$ \\
\hline $\mathrm{T} \times \mathrm{L}$ & 3 & 0.9 & 1.9 & 0.2 & 0.3 & 3.6 & 3.7 \\
\hline Replicates $\times \mathrm{T} \times \mathrm{L}$. & 8 & 0.4 & & 0.7 & & 1.0 & \\
\hline Genotypes (G) & 19 & 19.3 & $369.4 * *$ & 27.8 & $71.4 * *$ & 39.3 & $192.3^{* *}$ \\
\hline$G \times T$ & 57 & 0.05 & 0.9 & 0.4 & 1.1 & 0.2 & 1.1 \\
\hline $\mathrm{G} \times \mathrm{L}$ & 19 & 0.08 & 1.6 & 0.3 & 2.1 & 2.5 & $12.1^{* *}$ \\
\hline$G \times T \times L$ & 57 & 0.05 & 0.3 & 0.4 & $2.6^{* *}$ & 0.2 & 1.5 \\
\hline Rest & 152 & 0.2 & & 0.2 & & 0.1 & \\
\hline \multicolumn{8}{|l|}{1976 experiment } \\
\hline Temperature $(T)$ & 3 & 32.8 & $86.0^{* *}$ & 27.6 & $39352.6 * *$ & 26.2 & $10.9 *$ \\
\hline Light intensity $(\mathrm{L})$ & 1 & 38.3 & $100.5^{* *}$ & 50.1 & $71424.0^{* *}$ & 76.9 & $31.9^{*}$ \\
\hline $\mathrm{T} \times \mathrm{L}$ & 3 & 0.4 & $7.9^{* *}$ & 0.001 & 0.002 & 2.4 & $49.2^{*}$ \\
\hline Replicates $\times \mathrm{T} \times \mathbf{L}$ & 8 & 0.05 & & 0.4 & & 0.05 & \\
\hline Genotypes (G) & 9 & 8.4 & $211.9 * *$ & 16.9 & $134.4 * *$ & 6.1 & $60.9^{*}$ \\
\hline$G \times T$ & 27 & 0.1 & $2.5^{*}$ & 0.3 & $2.5 * *$ & 0.1 & 1.3 \\
\hline $\mathbf{G} \times \mathbf{L}$ & 9 & 0.04 & 0.9 & 0.1 & 0.9 & 1.5 & $15.0^{* *}$ \\
\hline $\mathrm{G} \times \mathbf{T} \times \mathrm{L}$ & 27 & 0.04 & 0.5 & 0.1 & 1.7 & 0.1 & 0.9 \\
\hline Rest & 72 & 0.07 & & 0.07 & & 0.1 & \\
\hline
\end{tabular}

${ }^{*} \mathrm{P}<0.05 ;{ }^{* *} \mathrm{P}<0.01$.

between results from the glasshouse and those from $10{ }^{\circ} \mathrm{C} \mathrm{HI}$ and $14{ }^{\circ} \mathrm{C} \mathrm{LI}$ in the phytotron. This implies that under certain controlled conditions an indication can be obtained about behaviour to be expected under fluctuating environmental conditions in the glasshouse.

\section{Analyses of variance for leaf number over all environments}

To investigate genotype $\times$ environment interactions for leaf number, analyses of variance over all phytotron environments per harvest time were carried out for 1975 and 1976. As analyses of variance per environment revealed no systematic differences between environments for coefficients of variation, ln transformation of leaf number was carried out. Results are presented in Table 5.

Main effects

As for plant weight significant differences also occurred for leaf number in both experiments with all harvests between temperatures, between light intensities and between genotypes.

Interactions

Significant interactions occurred with almost all harvests both in 1975 and 1976 . 


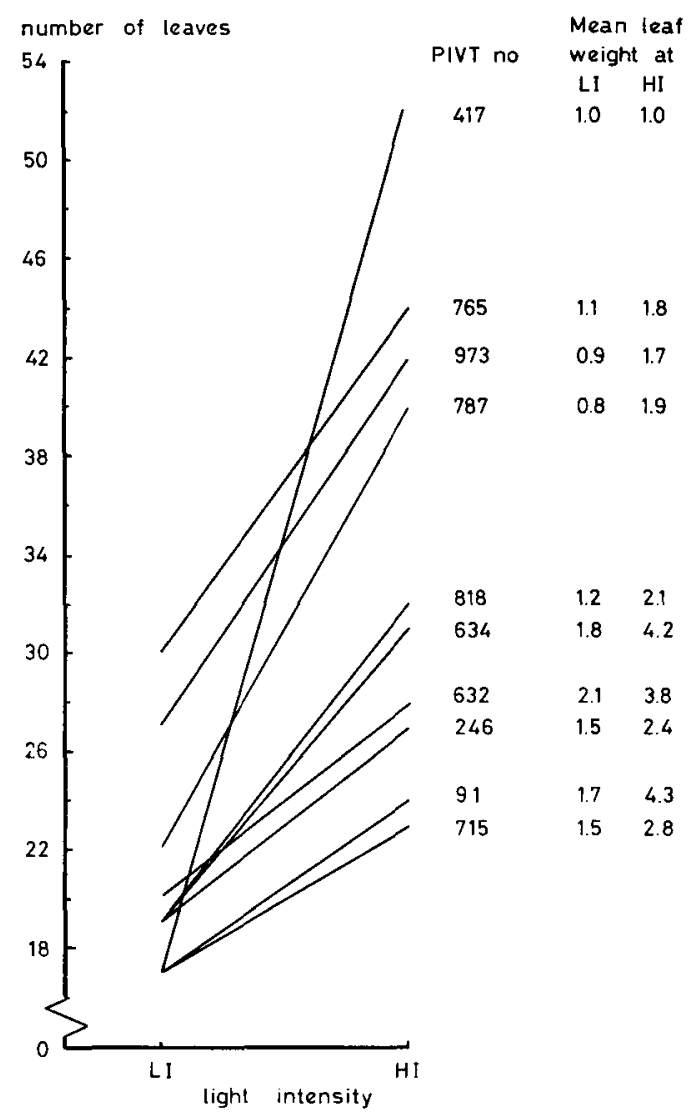

Fig. 9. Mean leaf number and mean leaf weight at $14{ }^{\circ} \mathrm{C}$ and two light intensities (HI and LI) of the 1976 experiment (harvest 3 ).

Though several interactions were relatively small, certain of these effects (e.g. $\mathrm{T} \times \mathrm{L}$ and $\mathrm{G} \times \mathrm{L}$ with harvest 3 in 1976) were of the same magnitude as the main effects.

$-G \times T$. A significant $\mathrm{G} \times \mathrm{T}$ effect only occurred with harvest 1 and 2 of the 1976 experiment. This interaction resulted from differences between genotypes for the temperature at which the largest number of leaves developed. The majority of the genotypes formed the maximum number of leaves at 17 or $20^{\circ} \mathrm{C}$ only a few did so at $14{ }^{\circ} \mathrm{C}$. No relationship existed between plant type and the temperature at which the maximum number of leaves was formed.

$-G \times L$. Both in 1975 and 1976 a significant $G \times L$ interaction occurred with harvest 3. This interaction is demonstrated in Fig. 9 where the effect of light intensity at $14{ }^{\circ} \mathrm{C}$ on leaf number is shown. This figure is representative of leaf formation at other temperatures. It appears that especially PIVT 417 is responsible for $\mathrm{G} \times \mathrm{L}$ interaction. At LI this genotype developed the smallest number of leaves and at $\mathrm{HI}$ the highest.

Mean leaf weights indicated in the figure show that the leaves developed at $\mathrm{HI}$ 


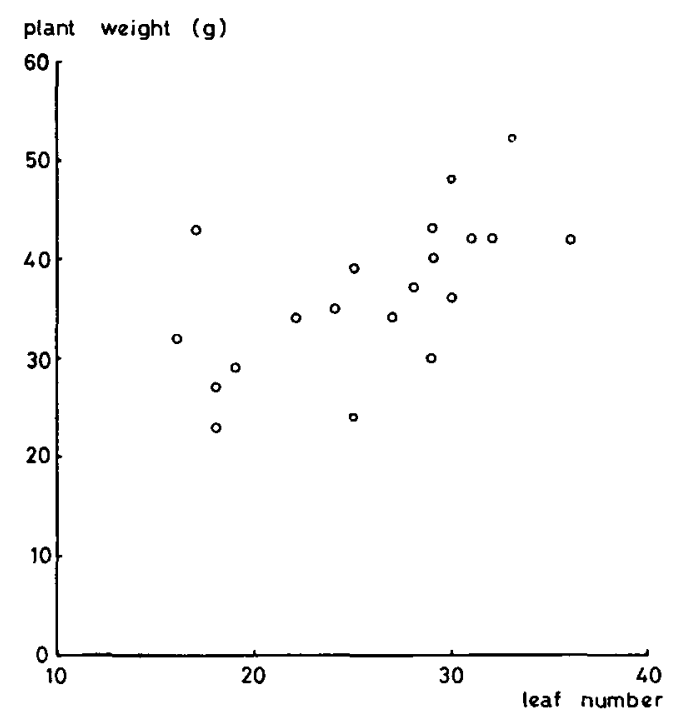

Fig. 10. Relationship between mean leaf number and mean plant weight for 20 PIVT numbers with harvest 3 in 1975 at $14^{\circ} \mathrm{C} \mathrm{LI}$.

by PIVT 417 were as small as those formed at LI. Genotypes like PIVT 91 and PIVT 634 with a rather small increase of leaf number at HI, compared to LI, developed large leaves at $\mathrm{HI}$ while the leaves which were formed at LI were small. This difference in reaction, few but large leaves versus many small leaves implies that the relationship between plant weight and number of leaves may depend on the environment. From graphs per environment in which this relationship was investigated it appeared that only in $14{ }^{\circ} \mathrm{C} \mathrm{LI} \mathrm{(1975)} \mathrm{a} \mathrm{clear} \mathrm{positive} \mathrm{relationship} \mathrm{between} \mathrm{these}$ characters existed. The presence and absence of this relationship are shown in Fig. $10\left(14{ }^{\circ} \mathrm{C} \mathrm{LI}\right)$ and $11\left(20^{\circ} \mathrm{C} \mathrm{LI}\right)$ respectively for the same genotypes.

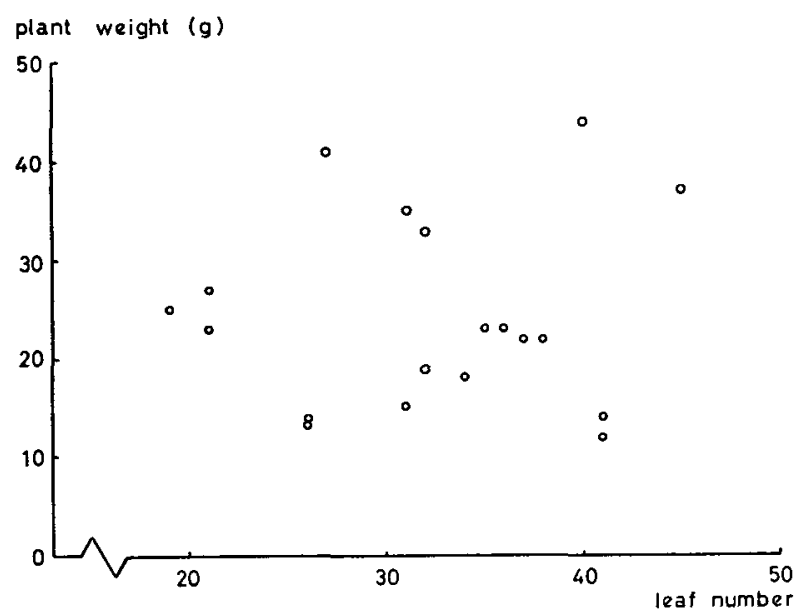

Fig. 11. Relationship between mean leaf number and mean plant weight for 20 PIVT numbers with harvest 3 in 1975 at $20^{\circ} \mathrm{C}$ LI. 


\section{GENOTYPE $\times$ ENVIRONMENT INTERACTIONS WITH LETTUCE}

Table 6. Effect of light intensity on leaf number at four temperatures with harvest 3 in 1976.

\begin{tabular}{lllll}
\hline Light intensity & \multicolumn{4}{l}{ Leaf number } \\
\cline { 2 - 5 } & $10^{\circ} \mathrm{C}$ & $14{ }^{\circ} \mathrm{C}$ & $17{ }^{\circ} \mathrm{C}$ & $20{ }^{\circ} \mathrm{C}$ \\
Highest intensity (HI) & 27 & 34 & 36 & 42 \\
Lowest intensity (LI) & 14 & 21 & 26 & 31 \\
& & & & \\
Absolute effect (HI-LI) & 13 & 13 & 10 & 11 \\
Relative effect (HI/LI) & 1.9 & 1.6 & 1.4 & 1.4 \\
\hline
\end{tabular}

From a breeding point of view it will be attractive if formation of large leaves could be combined with the formation of a great number of leaves, resulting in higher plant weights.

$-T \times L$. The interaction for $\mathrm{T} \times \mathrm{L}$ was only significant in 1976 with harvests 1 and 3 and is demonstrated in Table 6. The table shows both the absolute effect (HI-LI) and the relative effect (HI/LI) of light intensity on leaf formation per temperature.

Practically no differences between temperatures occurred for the absolute effect. This can also be seen in Fig. 4 where the lines for mean leaf formation at $10-20{ }^{\circ} \mathrm{C}$ at $\mathrm{HI}$ and LI run rather closely parallel.

The relative effect of light intensity was greatest at $10{ }^{\circ} \mathrm{C}$ and decreased with increasing temperature as was found for plant weight (see Table 4).

$-G \times T \times L$. A significant $\mathrm{G} \times \mathrm{T} \times \mathrm{L}$ interaction only occurred in 1975 with harvest 2 . This interaction implies that with certain genotypes the temperature at which the largest number of leaves developed, depended on light intensity.

- $G \times$ harvest. Comparison of sequence numbers for genotypes per harvest time for the three harvests per year involved, did not show clear genotype $x$ harvest interactions.

$-G \times$ year. A genotype $\times$ year interaction for harvest 3 , investigated for the four PIVT numbers which were tested in both years, by comparing sequence numbers, revealed that such an interaction occurred. This was a result of leaf formation of PIVT 417 which developed far more leaves at $\mathrm{HI}$ in 1975 than in 1976.

Comparison of leaf number in phytotron environments with that in the glasshouse environment

Comparison of the genotype sequence from largest leaf number to smallest leaf number of the glasshouse trial with those of the phytotron trials revealed a rather great similarity especially with the LI environments. So this similarity for leaf number was somewhat greater than for plant weight.

\section{Genotype $\times$ environment interaction analyses according to Eberhart $\&$ Russell}

To obtain an overall view of the 'interacting ability' of all the genotypes tested, Eberhart-Russell analyses (1966) were carried out for plant weight and leaf number. 
Instability or stability responsible for the presence or absence of genotype (G) $\times$ environment $(\mathrm{E})$ interactions are indicated by regression coefficients (b) per genotype. If $b$ is about 1 this implies a mean stable behaviour, if larger than 1 an unstable behaviour and smaller than 1 a very stable behaviour. Another parameter for (in)stability of a genotype is the deviation from regression indicated by $\mathrm{s}_{\mathrm{d}}{ }^{2}$.

Analyses for both characters were carried out with and without ln transformation for harvest 3 in 1975 and 1976. Analyses for plant weight without ln transformation revealed a very significant $G \times E$ interaction effect for $b$ in 1975 and 1976. After analysis with in transformation this effect was no longer significant. However the sequences for $b$ and $s_{d}{ }^{2}$ of the various genotypes from both analyses were rather similar. Analyses for leaf number with or without $\ln$ transformation gave similar results.

For our final overall impression we are, from a breeders' point of view, mainly interested in absolute, not transformed, differences for plant weight and leaf number between genotypes in the various environments. For this reason we give only the results of analyses without In transformation and neglect differences between error variances for environments, inflation of these variances by a component due to nonadditivity and the proportional nature of certain effects.

Results of these analyses are shown in Table 7 in which means, regression coefficients and $\mathrm{s}_{\mathrm{d}}{ }^{2}$ 's for plant weight and leaf number for harvest 3 of the PIVT numbers tested in 1975 and 1976 are given.

\section{Plant weight}

Means per genotype shown in Table 7 indicate the level of their regression line Certain genotypes such as PIVT Nos 91 (1975, 1976), 197 (1975), 417 (1975, 1976) and 632, 634 and 715 (1976), distinguished themselves from the others by high overall means. No clear relationship occurred between planttypes, as distinguished in Table 7 , and the overall means, though rather often non-heading cultivated types had high overall means.

The majority of the genotypes for which $b$ was about 1 had a mean stability. Others such as PIVT Nos 85,91, 197, 417, 634 and 715 had a large b indicating unstable behaviour. So these genotypes react very positively to favourable environments. Some genotypes such as PIVT Nos 246 and 765 had a rather small b which implies a very stable behaviour so a rather indifferent reaction to favourable and or unfavourable environments.

Among genotypes with a $\mathrm{b}$ greater than, equal to or smaller than 1 , PIVT numbers occurred with a large $s_{1}{ }^{2}$ implying another factor for instability.

There seems to be some relationship between plant type and $b$ value. In all heading cultivated types $b$ was equal to or smaller than 1 , while for the majority of the non-heading cultivated types $b$ was rather large. Wild species had a small or a large $b$.

\section{Leaf number}

Large differences between overall means per genotype occurred. Especially the cultivated non-heading types had rather small means compared with the heading types. 


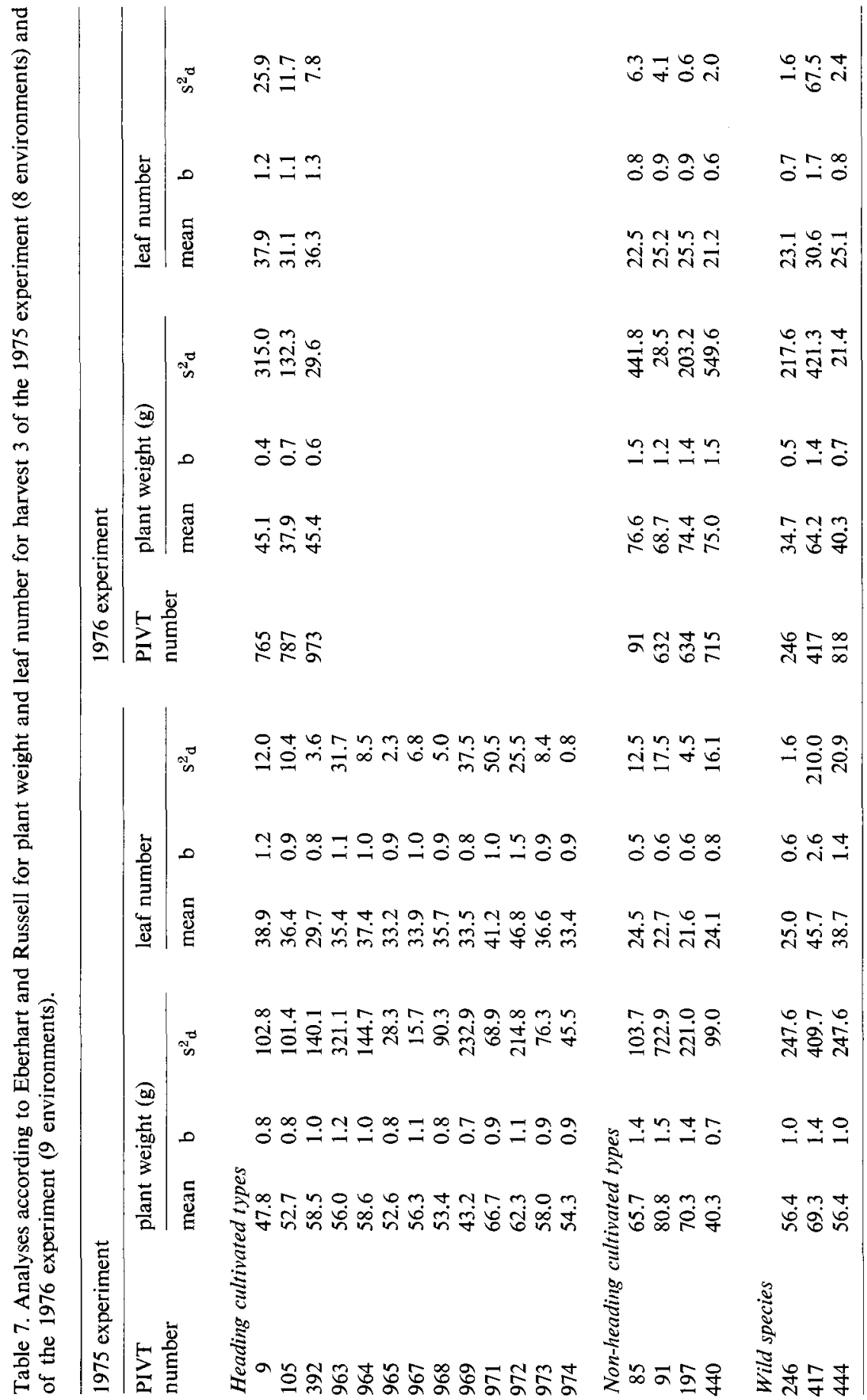


Both in 1975 and 1976 with a rather great number of genotypes b was about 1 , implying mean stability. Certain genotypes such as PIVT Nos 444, 972, and especially 417 , had a rather large $b$, which means that these genotypes react very positively to favourable environments, other genotypes had a small b (e.g. PIVT Nos 85, 91, 197, 246 and 715). Among PIVT numbers with a large, medium or small $b$ there were genotypes with a large $\mathrm{s}_{\mathrm{d}}{ }^{2}$.

For leaf number there is also a relationship between $b$ values and plant type, but here the opposite occurs as for plant weight. All non-heading cultivated types had a small $b$, while the heading cultivated types both could have a large or a rather small b.

The above means that no relationship existed between the stability or instability (expressed in b) of a genotype for plant weight and leaf number. This agrees with the results mentioned before, which showed that in many environments no clear relationship occurred between leaf number and plant weight.

\section{Discussion and implications for plant breeding}

The above results of research on genotype $\times$ environment interactions show that such interactions do occur. In certain cases interaction effects were rather great, in other cases they were rather small. To some extent the interactions depended on developmental phase, and they mostly increased at later harvesting. Though no clear genotype $\times$ harvest interactions were found the above implies that results from selection at early developmental phases may not correspond completely with those at the time of normal harvesting. Therefore early selection is not desirable. Results from selection in different years may also not correspond completely, at least as far as leaf number is concerned, because for this character a significant genotype $\times$ year interaction existed. Also because of the absence of a clear relationship between leaf number and plant weight in many environments, selection based on leaf number only is risky.

Physiological backgrounds for $\mathrm{G} \times \mathrm{T}, \mathrm{G} \times \mathrm{L}, \mathrm{T} \times \mathrm{L}$ and $\mathrm{G} \times \mathrm{T} \times \mathrm{L}$ interactions could hardly be explained by the available data; further research has to be done.

In an investigation carried out by Maxon Smith (1976) no genotype $\times$ environment interactions with lettuce were found. This might be due to the absence of large genetic differences between selections tested or to rather small differences between environments used.

Because of the genotype $\times$ environment interactions discussed in this paper it may be questioned whether stable $\left(b \leqslant 1\right.$, small $s_{d}{ }^{2}$ ) or unstable $\left(b>1\right.$, small $\left.s_{d}{ }^{2}\right)$ genotypes should be bred for growing under poor energy conditions. The latter should be able to grow at unfavourable conditions at least as well as winter varieties used until now. As a result of their ability to react extremely positively on occasional sunny days in winter, they will grow better than the stable types. For instance, PIVT 91 is an unstable type for plant weight, which grew very well in the glasshouse in winter under poor energy conditions with an occasional sunny day, and also in favourable phytotron environments. But in winters with a low light intensity 
throughout the growing period, rather comparable with phytotron environments at $10{ }^{\circ} \mathrm{C} \mathrm{HI}$ and LI, this genotype can hardly compete with others because it does not grow as well as certain normal winter varieties do under constantly poor energy conditions (see e.g. PIVT 971). Genotypes with a stable behaviour are only acceptable if they show a rapid growth even in constantly poor energy conditions and if they can compete with unstable genotypes in more favourable circumstances.

Because in the Netherlands weather in winter is unpredictable, combination of the two abilities - rapid growth in poor energy conditions and an extremely positive reaction to favourable environments - seems most attractive.

So far no 'complex growing types' as described above have been obtained. Maybe they can be produced by genetic recombination because both parental types are available. Unstable genotypes were found which grew well in most environments investigated and grew only worse in extremely unfavourable environments. On the other hand stable genotypes occurred which grew relatively well in very unfavourable conditions.

Development of such 'complex growing types' may have certain implications for selection procedure. For instance, it remains questionable under what environmental conditions selection should be carried out. With selection under constantly poor energy conditions the instability character may be overlooked. Selection at varying temperatures, however, as has been done until now, incurs the risk that genotypes with the stable character which are able to grow relatively well at constantly poor energy conditions, will not be selected. Recurrent selection for several years might overcome this problem to a certain extent. It should be noticed that until now breeding lettuce for winter growing in the Netherlands, which was carried out according to this procedure, mainly resulted in varieties with mean stability $(b \approx 1$; see Table 7).

Another alternative might be the testing of genotypes in two completely different environments, one with constant poor energy conditions and the other with rather high temperature and light intensity. In the former environment the ability of the genotypes to grow in poor energy conditions could be investigated; both environments together will give an impression of 'interacting ability'. For such environments those could be chosen which are most discriminating as indicated in Fig. 1 and 2 by large $F$ genotypes. Testing plants in two environments may be applicable for gene bank screening and for investigation of growth rate of (rather) homogeneous breeding populations (e.g. $F_{1}$ 's, $F_{3}$ 's, $F_{4}$ 's etc.). However, when segregating populations $\left(\mathrm{F}_{2}\right.$ 's) have to be investigated one test environment should be preferred. Such an environment might be the one described for screening purposes of the gene bank. In this environment with usually poor energy conditions alternating with occasional high temperature and light intensity as a result of sunny days, both the ability to grow well in poor energy conditions and the 'interacting ability' might be expressed. Genotypes with both abilities might be distinguished because of an extremely good growth under such conditions. 
A. H. EENINK AND L. SMEETS

\section{Acknowledgments}

We are indebted to Mr J. C. van Oeveren for technical assistance, to Miss F. Garretsen, Mr J. Kamminga and Miss F. Bos for help in statistical analysis, and to our colleagues for critically reading the manuscript.

\section{References}

Eberhart, S. A. \& W. A. Russell, 1966. Stability parameters for comparing varieties. Crop Sci. 6: $36-40$.

Eenink, A. H., 1977. Breeding lettuce for winter. Grower 27 (Suppl.) (Jan.) 16-17.

Maxon Smith, J. W., 1976. Genotype-environment interaction in glasshouse lettuce. Hort. Res. 16: 37-43. 